\title{
Processes and priorities in planning mathematics teaching
}

\author{
Peter Sullivan • David J. Clarke • Doug M. Clarke • \\ Lesley Farrell • Jessica Gerrard
}

Received: 2 April 2012 /Revised: 3 October 2012 / Accepted: 5 December 2012 /

Published online: 18 December 2012

(C) Mathematics Education Research Group of Australasia, Inc. 2012

\begin{abstract}
Insights into teachers' planning of mathematics reported here were gathered as part of a broader project examining aspects of the implementation of the Australian curriculum in mathematics (and English). In particular, the responses of primary and secondary teachers to a survey of various aspects of decisions that inform their use of curriculum documents and assessment processes to plan their teaching are discussed. Teachers appear to have a clear idea of the overall topic as the focus of their planning, but they are less clear when asked to articulate the important ideas in that topic. While there is considerable diversity in the processes that teachers use for planning and in the ways that assessment information informs that planning, a consistent theme was that teachers make active decisions at all stages in the planning process. Teachers use a variety of assessment data in various ways, but these are not typically data extracted from external assessments. This research has important
\end{abstract}

\footnotetext{
P. Sullivan $(\bowtie)$

Faculty of Education, Monash University, Clayton 3800, Australia

e-mail: peter.sullivan@monash.edu
}

\section{J. Clarke}

International Centre for Classroom Research, Melbourne Graduate School of Education, University of Melbourne, 109 Barry Street, Carlton, Melbourne, VIC 3053, Australia e-mail: d.clarke@unimelb.edu.au

\section{M. Clarke}

Mathematics Education, Mathematics Teaching and Learning Research Centre, Australian Catholic University (Melbourne Campus),

115 Victoria Parade, Fitzroy, VIC 3065, Australia

e-mail: doug.clarke@acu.edu.au

\section{Farrell}

Research and Development, Faculty of Arts and Social Sciences, UTS Sydney, UTS CRICOS Provider Code 00099F, PO Box 123, Broadway, NSW 2007, Australia e-mail: lesley.farrell@uts.edu.au

\section{J. Gerrard}

Faculty of Education, University of Melbourne, Melbourne, Australia 
implications for those responsible for supporting teachers in the transition to the Australian Curriculum: Mathematics.

Keywords Mathematics curriculum - Resources · Planning - Assessment - Teacher education

\section{Introduction}

The implementation of the new Australian Curriculum: Mathematics (AC:M) provides an opportunity to improve the teaching and learning of mathematics. The following is a report of one aspect of the first phase of a research project ${ }^{1}$ that is focussing on resources, systems and developmental experiences that can support teaching and learning, documenting ways in which those who implement the new curricula aim to align their interpretations, practices and policy decisions, an approach described by Ball (1997) as 'peopling policy'. The project is also examining the implementation of the Australian Curriculum: English but only the results related to mathematics planning are presented in this paper.

In the development of the AC:M, the over-arching The Shape of the Australian Curriculum (ACARA, 2012) outlines the rationale and guiding principles for its development. That document explains the decision to develop discipline specific curriculum, and also describes the structures and processes to be used to build connections between those disciplines and to ensure that current issues are addressed. The overall Australian Curriculum, in addition to the discipline specific documents, describes cross curriculum priorities (e.g., Aboriginal and Torres Strait Islander histories and cultures), and general capabilities (e.g., numeracy, creative and critical thinking). The accompanying Mathematics Shape Paper (ACARA, 2012), which outlines principles to inform the mathematics curriculum, including that:

- the content be succinctly and clearly described to support teacher decision making;

- the process strands, which are termed proficiencies (understanding, fluency, problem solving and reasoning), be integrated with the content strands;

- the curriculum be less "crowded" allowing for greater depth of study;

- the most capable students be extended by engaging with sophisticated ideas within basic topics rather than moving quickly to more advanced topics; and

- there be greater attention to statistics and probability at all levels of schooling.

Subsequent drafts of documents constituting the AC:M interpret these principles, outlining content descriptions and elaborations, achievement standards, and annotated student work samples.

\footnotetext{
${ }^{1}$ This is a report of the Peopling Education Policy project that is funded by the Australian Research Council (LP110100062) with additional funding provided by the NSW Department of Education and Communities, Victorian Curriculum and Assessment Authority, Catholic Education Office Melbourne and the Australian Curriculum Assessment and Reporting Authority. The project is collaboration between Monash University, Australian Catholic University, University of Melbourne, University of Newcastle, University of Sydney, and University of Technology Sydney. The content is the responsibility of the authors and the views expressed do not necessarily represent the views of the universities or the partners.
} 
Our project is particularly interested in how, and to what extent, teachers use such documents in their enactment of the AC:M, how the documents are interpreted and used across systems, the effects of such documents on teachers' intentions to act, and, in particular, the implications of such documents for the reconstruction of teacher knowledge and teaching practices (Yates \& Grumet, 2011). This project is therefore not an evaluation of the quality of the AC:M, but rather a study of how the AC:M informs and influences system, school and individual teacher decisions. It also provides a basis for developing understanding of the changes expected in teachers' work for AC:M enactment in classrooms, and thus establishing the support required for teacher learning. The particular focus of this report is on the sources of curriculum authority that teachers consult, their connection of important mathematical ideas with curriculum planning, the ways that teachers plan, and the ways in which they use assessment information in that planning.

This is a collaborative project with universities and state and federal jurisdictions as partners. It was initiated because of a shared belief that the multiple layers of work that different education systems undertake must align, to a significant extent, if classroom teaching and learning across Australia is to improve in the ways that all the partners hope it will. Studies have addressed the question of how teachers variously interpret and implement new curricula (e.g., Clements, 2006; Freebody \& Muspratt, 2008). The impact of a curriculum development intervention as farreaching as the AC:M, however, potentially extends far beyond classrooms. It is likely to have substantial ramifications for the various levels of administration, for the relationships within and between various jurisdictions and systems, and for ways in which work in those jurisdictions and systems in turn impacts on classrooms.

For this reason, we have conceptualised the enactment of the $\mathrm{AC}: \mathrm{M}$ as a somewhat more complex process than the straightforward dissemination of curriculum documentation. While the documentation itself is important, we know that teachers, school administrators and systems educators and bureaucrats will take up that documentation and use it in different ways depending on their immediate local circumstances, the social, political and cultural contexts in which they are operating, the material resources available to them and the pragmatic constraints and opportunities of their work settings, amongst many factors. New documents, including both original formulations and new articulations of the curriculum documents, may be developed to meet the perceived needs of people working in distinctive local settings. Some of these documents, like State curriculum documents, may carry their own regulatory authority while others, like those developed by colleagues or professional associations, may be intended to address specific local concerns. For this reason we prefer to think of the AC:M as dynamic practice in which teachers, schools and systems 'take up' (Braun et al. 2011), 'appropriate' (Levinson et al. 2009), or 'enact' (Heinmans, 2011) the curriculum articulated in the formal documents. This is not to say that formal curriculum policy documents like the AC:M do not have major effects on classrooms and teachers, clearly they do (Hamilton 2009). It is simply to acknowledge that the curriculum that students experience in classrooms is the product of a complex web of decision-making which is shaped, but not determined, by the formal curriculum documentation.

Indeed, informal and formal curriculum documentation is foundational to the processes of planning, teaching and assessment. As demonstrated in the Hattie and 
Timperley (2007) review of a large range of studies on the characteristics of effective classrooms, curriculum-based feedback is a significant influence on student achievement. They identified the key elements as being that students receive information on "where am I going?", "how am I going?", and "where am I going to next?". Such research suggests that to plan teaching, to advise the students interactively, and to assess learning, it is important for teachers to know and be able to articulate their intentions. The fundamental assumption is that teachers are best able to support students when they know what they hope students will learn. This has significant implications for the practices of curriculum interpretation, translation and enactment as teachers work to realise the $\mathrm{AC}: \mathrm{M}$ in their classrooms. Exploring this further, in this article we draw on the initial stages of data collection in our project to examine the relationship between curriculum interpretation and teachers' planning processes. Specifically, presenting results from a survey of Australian teachers, we describe ways that teachers report that they use curriculum and other documents generally in their planning and assessment. While, at the time of writing, the implementation of the AC:M is at early stages, the ways that teachers address such issues are of interest internationally, not just in Australia.

\section{Curriculum knowledge and curriculum planning}

Curriculum knowledge and intentions are central to the sorts of decisions teachers make on planning. In order to conceptualise the categories of knowledge used by teachers for the teaching of mathematics we draw on Hill et al. (2008) diagrammatic schema that represents two major categories: subject matter knowledge; and pedagogical content knowledge. In this schema, the sub-categories of Subject Matter Knowledge are: common content knowledge; specialised content knowledge; and knowledge at the mathematical horizon. The sub-categories of Pedagogical Content Knowledge are knowledge of content and teaching; knowledge of content and students; and knowledge of curriculum. Whilst providing a useful representation of the different forms of knowledge that inform teachers' decision-making, Hill and colleagues did not elaborate what they meant by the term 'knowledge of curriculum.' Indeed, as Choppin (2009) recently noted, there is increasing need within the mathematics education community to turn to a consideration of teachers' curriculum knowledge (see also Sherin \& Drake, 2009). Thus, elaborating this schema, we draw on Shulman's (1986) earlier discussion of teachers' curriculum knowledge:

The curriculum is represented by the full range of programs designed for the teaching of particular subjects and topics at a given level, the variety of instructional materials available in relation to those programs, and the set of characteristics that serve as both the indications and contraindications for the use of particular curriculum or program materials in particular circumstances. (p. 10)

Note that this definition does not mention knowledge of the type of curriculum documentation that has been produced by the various Australian jurisdictions previously, and is (at the time of writing) being disseminated by ACARA.

The assumption mentioned above is that knowledge of curriculum informs planning. Yet, the ways in which teachers come to enact curricular knowledge in their 
planning is both an individual process influenced by teachers' beliefs and understandings of teaching and learning (e.g., Drake \& Sherin, 2006), and highly dependent on schooling context. In the United States, for example, authors imply that teachers take text resources and the associated teachers' guides as the curriculum, and plan their teaching from there. Superfine (2008) described teachers as "curriculum implementers and not curriculum planners" (p. 12). She reported an intensive study of teacher planning and proposed a mathematics instruction model that includes three phases: mathematics curriculum materials, teachers' conceptions, and planning problems. The term 'planning problems' refers to the actions teachers take to further children's understanding of mathematics. Remillard et al. (2009) went so far as to describe the planning process as "transforming curriculum ideals, captured in the form of mathematical tasks, lesson plans, and pedagogical recommendations into real classroom events" (p. 1). In other words, they limit curriculum ideals to tasks, lesson plans and pedagogies and do not mention overall documents listing content descriptions. Remarkably, Remillard investigated the research literature on teachers' use of curriculum materials and her substantial review article (Remillard, 2005) made only two references to teacher planning, and in each instance the cited "curriculum document" was the textbook. Such limited reference equates to a major silence in the research literature on teacher use of official curriculum documents to inform their planning. Kilpatrick et al. (2001) argued that planning is critical, takes much effort and is the core activity of experienced teachers. Yet they claimed that the planning of US teachers consists of choosing activities and ways in which they will organise the activities. Similarly, the significant research of teaching reported by Stein et al. (1996) described the initial phase in planning as the teacher taking the mathematical task as presented in instructional materials, which, influenced by the teacher's goals, subject matter knowledge, and knowledge of students, informs the way they teach. In other words, instructional materials are taken to constitute the curriculum, and the student and teacher textbooks are understood as the starting point for such planning as occurs.

In a different context, describing the processes used by Japanese teachers, Fernandez and Cannon (2005) argued that Japanese teachers focus on ensuring that students discover concepts and develop a positive approach to their learning. Drawing on two further cultural contexts, in reporting a study of teacher planning from Sweden and Hong Kong, Holmqvist and Wennås Brante (2011) noted marked differences between the ways such teachers plan. The Swedish teachers focused on activities and teaching methods, which they considered separately from the content, whereas the Hong Kong teachers considered the content at all stages concurrently with the methods. Jin (2012), in describing the planning and teaching of mathematics in Chinese schools, argued that the content is taken as a given and that planning focuses on processes for reviewing existing knowledge, building a bridge to new knowledge, summarising the learning and developing variations on the learning to prompt transfer to new contexts. None of these studies argued for a significant role of centrally determined curriculum documents and the role of assessment seems hardly to be mentioned.

In relation to international comparative research, Keitel and Kilpatrick (1999) questioned the treatment of the mathematics curriculum as unproblematic and suggested that the spectre of an "idealized international curriculum" lies behind even the 
most sophisticated research designs, including text and document analyses and the use of video to study classroom practice.

A pseudo-consensus has been imposed (primarily by the English-speaking world) across systems so that curriculum can be taken as a constant rather than a variable, and so that the operation of other variables can be examined. (Keitel \& Kilpatrick, 1999, p. 253)

Such a stance glosses over local curriculum authorship as irrelevant in evaluative comparisons of teaching practice, teacher knowledge and student achievement.

Thorsten (2000) makes a related point that while the conduct of much of international comparative research in mathematics education seems predicated on assumptions derived from conceptions of a global mathematics curriculum, the local interpretation of the results of such research will always be framed by politicians, policy makers and curriculum developers in terms of national rather than international aspirations, values, needs and conditions. This pragmatic honouring of local curricular knowledge and authorship sits in paradoxical contrast to general theorising about classroom practice and student learning, which discards teacher curricular knowledge as a significant explanatory variable.

Given the current development of the first nationally defined centralised mathematics curriculum in Australia, there is therefore pressing need to develop understanding of how such documentation informs teaching practices. Certainly, the assumption at the systems-level across the different States and Territories is that official formal curriculum documentation plays a foundational role in teachers' planning. Reiterating this sentiment, the AC:M is also based on the notion that it forms the foundational basis for teachers' curriculum planning and decision making. It is, however, not clear how documented curriculum policy is animated to become curriculum practice - the order in or extent to which such documents are consulted, the ways that teachers interpret such documents, or the extent to which such documents inform teaching. That is the focus of the data reported below.

\section{The context and methods of the data collection}

The overall focus of our project is on describing influences on teachers' knowledge and practice, and especially on ways teachers interpret and use curriculum documents. The project is using an adaptation of the schematic of Clark and Peterson (1986) that describes relationships between aspects of knowledge, situational factors, and teachers' intentions. The bolded headings of the boxes represent the different elements of our interest. The dot points illustrate the type of issues that are relevant within each box.

In particular, in the data presented below, the focus is on issues such as authority, knowledge of important mathematical ideas, planning processes and assessment practices related to planning.

We had no preconceptions about the types of documents that teachers consult, the authority they attribute to those documents, the role of their experiences, the resources to which they may have access, and so on,. To gain an understanding of these 
matters we first conducted eight focus groups of primary teachers and four focus groups of secondary teachers. We made use of fortuitous access to groups of teachers meeting for other purposes such as participation in higher degree programs or in teacher professional development programs. If any systematic bias was associated with the constitution of these focus groups, it was towards the inclusion of more senior mathematics teachers, who we might expect to be better informed regarding school practice and have a more comprehensive knowledge of the range of curricular resources available to teachers. Such focus group membership could only improve the capacity of the survey instrument to anticipate a variety of curricular authorities and school practices. Within these focus groups, there was significant diversity of opinion about the role of such curricular resources as the textbook. Such diversity of opinion provided an ideal foundation from which to construct a suitably comprehensive survey instrument.

The prompts for those focus groups were intended to promote discussion among the teachers in order to explore commonality and difference in teachers' use of official curriculum documentation. For example, we presented participating teachers with extracts from the AC:M and asked questions such as: What does this extract mean to you? To what extent does this suggest changes to your current practices? What would you need to know to implement this aspect of the curriculum in your classroom? How might you assess whether students learn the content suggested by the curriculum content descriptions? How might this influence your planning?

The focus group interviews were recorded and transcribed, and the transcripts analysed to identify recurrent themes in the teachers' responses. These themes were used to provide the structure of a survey intended for face-to-face and online completion by teachers nationally. Preliminary subsets of draft survey items were administered to groups of teachers for the purpose of item validation. In particular, the inclusion of an open-ended "other" response with most trialled items led to the identification and inclusion of a small number of additional item elements. The result of this item refinement and validation process was a survey that appeared readily comprehensible to teachers, while accommodating the range of alternative responses suggested by both the research literature, researcher experience, and teacher responses from the focus groups. Teachers were invited to complete an on-line version of the survey via a link on the web site of the Australian Association of Mathematics Teachers, and some groups of teachers to which we had occasional access through a variety of professional contexts completed a paper version of either the whole survey or selected components of the survey. Table 1 presents the background characteristics of those who completed the survey. While no claims are made that this sample represents Australian teachers generally, and it is recognised that the on-line responses are from teachers completing the survey in their own time and on their own initiative, the data in the table indicate some relevant background characteristics of the teachers. The types of background characteristics that are commonly accessed for similar research purposes include teacher gender, school type, geographic location, and teaching experience. The state in which the teacher is teaching is relevant in that the previous curricula in some states were quite different in structure and resourcing.

With the provisos that there was a disproportionally large percentage of primary responders from non-government schools (due to the nature of the face-to-face groups to which we had access), and fewer responses from Victorian secondary 
Table 1 Percentages of various background characteristics of survey respondents

\begin{tabular}{lll}
\hline & $\begin{array}{l}\text { Primary } \\
\text { teachers } \\
n=264\end{array}$ & $\begin{array}{l}\text { Secondary } \\
\text { teachers } \\
n=351\end{array}$ \\
\hline Surveys completed online & 56 & 93 \\
Female responders & 87 & 63 \\
Government school teachers & 31 & 61 \\
Based in Metropolitan schools & 61 & 56 \\
School based responders & 93 & 94 \\
Teaching for more than 20 years & 46 & 49 \\
Classroom teacher with additional & 27 & 52 \\
$\quad$ responsibility & & \\
Responders from NSW & 47 & 38 \\
Responders from Victoria & 20 & 12 \\
Responders from Queensland & 16 & 18 \\
\hline
\end{tabular}

teachers than we had hoped, the occurrence of participant characteristics in the other categories suggest that relevant sectors of the teaching community were represented adequately in the overall responses received. A total of $83 \%$ of responses were from the three largest states meaning the percentages from the other states were very small. Note that not all respondents completed all items, so some of the tables presented below have fewer responses.

Here we report in particular on the survey responses that focused on teachers' use of curriculum documentation and the relationship of this to:

1) teachers' expression of curriculum knowledge - the 'important ideas' and the manner in which these are sequenced and connected, which forms the basis of their teaching intentions;

2) the short- and long-term planning undertaken in order to organise the day-to-day teaching and learning activities; and

3) their use of assessment information in the interpretation and enactment of formal curriculum documentation.

In the survey, we also sought responses on the ways teachers address mathematical reasoning in their planning and teaching the choices they made in matching tasks to curriculum statements, and their professional learning needs in this regard, but these data are not reported here. The ethics approval was on the basis that participation was voluntary and anonymous, and this was the case. The time taken to complete the survey $21 \mathrm{~min}$ for secondary teachers and $18 \mathrm{~min}$ for primary teachers

With respect to this aspect of the project, the particular research questions were:

- What are the sources of curriculum authority that teachers consult to inform their planning?

- How do teachers describe the important ideas in the topic they are about to teach?

- What comparative emphasis do teachers place on activities or curriculum documents in their planning?

- What use do teachers make of assessment information to inform their planning and curriculum emphases? 


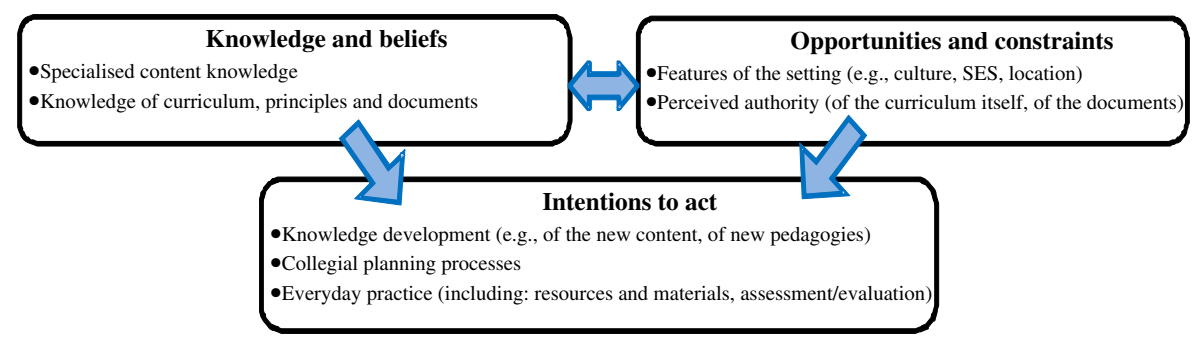

Fig. 1 Adaptation of the schematic of Clark and Peterson

While the model guiding data collection presented in Fig. 1 refers to the overall project, note that the first of these questions is part of the exploration of opportunities and constraints, the second question relates to teacher knowledge, and the third draws on both teacher beliefs and their intentions, and the fourth question is about their intentions.

\section{Results}

The results from selected aspects of the survey are presented in the following. There are four aspects presented: sources of curriculum authority; responses related to the important ideas in upcoming topics; responses related to planning processes; and responses related to the role of assessment information in planning. Recognising that the $\mathrm{AC}: \mathrm{M}$ is at the early stages of implementation (at the time of writing), the widespread nature of initial consultations on preliminary documentation and curriculum drafts, along with frequent publicity in the media about the curriculum, would have ensured that respondents would be aware of the existence, principles and structure of the curriculum even if not the specific details. The results are mainly descriptive to present the profile of the responding teachers, and the variations between teachers, with the intent that this information can inform subsequent teacher professional development. In each section the responses from secondary and primary teachers are presented separately because, based on the researchers' knowledge of the Australian school system, the context of primary and secondary schools, the backgrounds of the teachers, and their planning routines could be confidently assumed to be quite different.

\section{Sources of curriculum authority}

One of the goals of the survey was to ascertain the types of documents that teachers consult. In the survey, the teachers were presented with a list of possible resources to which they might refer at various stages. Respondents were asked to indicate whether they used those resources never/rarely, sometimes or often. The list of resource options offered was as follows:

\footnotetext{
State/territory curriculum/syllabus documents

State/territory developed support materials

Commercial publications/products, e.g. text books

Web-based curriculum materials and lesson ideas

School developed materials
} 
Individual/team developed materials

Professional Association materials (e.g. resources from AAMT)

NAPLAN test items/results

State assessment items/results

School-based assessment results

Results of my own assessments

Australian Curriculum documents

Australian Curriculum support materials (e.g. Australian Curriculum Connect)

Other (please state):

To offer another perspective on the sources of authority, the following prompt was posed: "If there was a major difference of opinion among your colleagues regarding what to teach, please rate which resources - if any-you would be likely to consult to resolve the problem". Respondents were asked to indicate whether they would be unlikely, neither likely nor unlikely, or likely to access the respective resources. The list of resources was as follows:

Text books

External assessment results, e.g. NAPLAN

School or class assessment results

Relevant official curriculum documents, e.g. NSW BOS Syllabus,

Australian Curriculum, VELS

State curriculum support materials

School-produced curriculum materials

Experienced colleagues

School-based curriculum leader

Regional or state support personnel

Professional Association personnel or materials

Other (please state):

Summaries of responses of teachers to each of these items are presented in the following sections.

Responses from secondary teachers

The first prompt asked the teachers to indicate how often they used the resources listed above in their YEARLY/TERMLY planning. The most common "often" responses from secondary teachers were (with the number of responders out of the total selecting the item as "often" in brackets):

Commercial publications /products. e.g., text books (156/216)

Results of my own assessments (154/218)

Individual/team developed materials (136/216)

State/territory curriculum/syllabus documents (135/216)

While the popularity of the commercial resources was not unexpected, it was surprising the extent to which teachers claimed to use their own assessments as the basis of yearly planning. Likewise, we had not expected that teachers' own materials would be accessed as frequently as formal documents. 
The teachers were also asked to indicate which of the resources listed above they used in their UNIT/WEEKLY planning. The most common "often" responses were

Commercial publications/products. e.g., text books $(156 / 215)$

Individual/team developed materials $(155 / 215)$

Results of my own assessments (118/215)

Again, the extent to which commercial texts are used in such planning is not surprising, but the use of locally developed resources and teachers' own assessment was unexpected.

In terms of the sources to which teachers would turn in resolving disputes, the most common "likely" responses, chosen from the list presented above, were:

Experienced colleagues (173/211)

Relevant official curriculum documents, e.g. NSW BOS Syllabus, Australian Curriculum, VELS (161/211)

School-based curriculum leader (145/211)

School or class assessment results $(110 / 211)$

In other words, the experienced colleagues were likely to be used to arbitrate issues as much as curriculum documents. Together the responses indicate a commitment to autonomous decision making and reliance on local authority that we did not predict. This is discussed further below.

Responses from primary teachers

The primary teachers were offered identical prompts and identical options to those for secondary teachers. In terms of choosing teaching and learning activities for YEARLY/TERMLY planning, the most common "often" responses from primary teachers were:

Results of my own assessments (148/202)

State/territory curriculum/syllabus documents (142/202)

Individual/team developed materials (112/202)

Web-based curriculum materials and lesson ideas (104/202)

The most common "often" responses from primary teachers in terms of UNIT/ WEEKLY planning were

Results of my own assessments (118/182)

Web-based curriculum materials and lesson ideas (104/183)

Individual/team developed materials (112/183)

In terms of resolving differences of opinion among colleagues, the most common "likely" sources to which the teacher reported they refer were:

Relevant official curriculum documents, e.g. NSW BOS Syllabus, Australian Curriculum, VELS (140/173)

School or class assessment results $(124 / 171)$ 
Experienced colleagues (121/171)

School-based curriculum leader (123/171)

Primary teachers claim to refer to web based resources rather than texts to inform their planning. Their own assessments of their students were also prominent, and, like the secondary teachers, they refer to local authorities in both planning and resolving disputes. These issues are discussed further below.

Identifying the important ideas in upcoming topics

We take teacher capacity to identify "important ideas" and their interrelationship, as indicative of a significant form of curricular knowledge. The prompts associated with the important ideas were posed not only to set the context for subsequent items in the survey, but also to elicit information useful for understanding aspects of the curricular knowledge and thinking behind teachers' planning. The teachers were asked to respond to the following prompts:

What is the next mathematics topic you are planning to teach?

What is the most important idea that you will focus on for that topic?

Nearly all teachers responded to the first prompt by listing a topic that was easily recognisable as part of the mathematics curriculum. The following discussion relates to responses to the second of these prompts. Before discussing the responses, it is worth noting that our original intention was that the "important ideas" prompt would elicit information on important mathematical ideas in the forthcoming topic. Hindsight might indicate that inserting mathematical into the prompt would be desirable. However, as is evident below, the more general structure gave teachers the opportunity to focus on aspects other than mathematical ones, if they chose to do so. The fact that the important idea in the teaching of a forthcoming mathematical topic in the mind of a teacher might not be mathematical is revealing in itself.

Responses from secondary teachers

The responses from secondary teachers were thematically coded. There were five categories of response identified and these are presented below, along with the associated topic. The first category of response we characterise as "A mathematical idea within the topic". Some illustrative examples are:

- measurement - difference between length, area and volume

- algebra - the concept of a variable

The second we characterise as "An element of a hypothetical learning trajectory". The following is an example.

- geometrical applications of calculus - an understanding of what the derivative actually means in terms of being able to interpret gradient functions, find critical points, and use these to sketch graphs 
The third we characterise as "a sub-topic of the larger mathematical topic". Examples of such responses, presented with their suggested topic, are as follows:

- algebra - terms and factors

- algebra-linear equations

The fourth category was "A statement which could apply to most other topics and not specifically an important idea tied to the particular topic":

- application in society

- applied geometry - the topics and sub-topics as outlined in the curriculum statements

The fifth category was "A statement which describes aspects of pedagogy and does not particularly address content"

- clearly articulating my aims to the students

While the teachers were able to clearly identify their next topic, fewer teachers than we might hope described the important ideas with sufficient clarity to give us confidence that they could use such ideas in their planning. For example, around $56 \%$ of the secondary teachers simply listed a sub-topic of the larger mathematical topic (e.g., measurement-perimeter and area), and $17 \%$ made a statement which could apply to most other topics and not specifically an important idea tied to the particular topic (e.g., real life applications). We speculate that these teachers, at least, would experience difficulty with this aspect of their planning.

Responses from primary teachers

The responses from primary teachers were similarly thematically coded. We used the same five categories of responses, and also present examples along with the topic they identified. The first we describe as "A mathematical idea within the topic":

- Area-you can measure area with informal units

- Division - a fair share and what to do with remainders

The second we describe as "An element of a hypothetical learning trajectory":

- addition of whole numbers - moving from counting all to counting on

- algebra - experimenting with and developing a range of strategies to solve simple equations

The third we describe as "a sub-topic of the larger mathematical topic". Examples of such responses are as follows:

- patterns and algebra-number patterns

- position-coordinates

The fourth category was "A statement which could apply to most other topics and not specifically an important idea tied to the particular topic": 
- multiplication and division - open ended tasks and language of concepts related to real life experiences:

- whatever is next in [the textbook]

The fifth category was "A statement which describes aspects of pedagogy and does not particularly address content":

Angles - where the kids are and start from that

Data — prior knowledge

On inspection it seems that around $32 \%$ of the primary teachers simply listed a sub-topic of the larger mathematical topic, and $13 \%$ made a statement which could apply to most other topics and which was not specifically an important idea tied to the particular topic. For these teachers, it seems that the notion of "important ideas" would not be helpful for them in their planning. This is discussed further below.

Planning processes

The items presented in this section follow on from the items discussed above. This prompt asked teachers to respond in the context of their responses to those items:

Rank the following statements in order from 1 to 6 in terms of "closeness" to what you will do when you are planning and teaching that mathematics topic (use 1 for most like you, 2 for the next most like you, etc.)

This connects directly to the "intentions to act" aspect of the schematic presented in Fig. 1. The focus is on meso planning of mathematics topics. The assumption is that macro planning is done by others at a different time, and micro planning of individual lessons happens subsequently.

\section{Secondary teacher responses}

Table 2 presents responses of the secondary teachers converted to a score to indicate the mean of the responses, and also the percentage of teachers who ranked the particular descriptor within the top two ranks in terms of closeness to what they would do. Not all responders completed this item. The mean ranking was calculated by adding the ranks allocated and calculating the mean. A mean ranking below 3 indicates that teachers have generally rated the statement as close to a description of their planning. The percentage of teachers ranking an item in the top two is to give a different measure of the closeness of the statement to the ways that teachers plan. An entry of $50 \%$, for example, would indicate that half of the teachers ranked the statement in their top two selections, indicating that the item is part of their planning routines.

The table indicates that the option referring to "collect[ing] relevant classroom activities" received a high ranking from the teachers and is considered in the top two options by $57 \%$ of the teachers. For this table, and for the following, comparative tables were prepared based on responses differentiated by age, experience, system, gender, or whether they completed the survey online. Because of the nature of the 
Table 2 Ranking of statements on specific planning process in order (secondary) $(n=138)$

\begin{tabular}{|c|c|c|}
\hline & Mean ranking & $\begin{array}{l}\% \text { Ranking this } \\
\text { in the top two }\end{array}$ \\
\hline $\begin{array}{l}\text { Based on what I know about the students already, I will collect the } \\
\text { relevant classroom activities to which I have access, choose the ones } \\
\text { that fit the topic, and then decide the order in which I will use them. }\end{array}$ & 2.5 & 57 \\
\hline $\begin{array}{l}\text { I will read the official curriculum documents to identify the } \\
\text { specific learning goals and then plan my teaching based on that. }\end{array}$ & 3.2 & 46 \\
\hline $\begin{array}{l}\text { I will look through a textbook or other teacher resource and plan } \\
\text { teaching which relates to the given content. }\end{array}$ & 3.3 & 34 \\
\hline $\begin{array}{l}\text { I will look at the school-based curriculum documents then identify } \\
\text { specific learning goals, and select activities from there that I will } \\
\text { use with my students. }\end{array}$ & 3.3 & 34 \\
\hline $\begin{array}{l}\text { I will meet with other teachers, we will share our experience and } \\
\text { ideas, then plan the activities and resources we will use. }\end{array}$ & 3.6 & 30 \\
\hline $\begin{array}{l}\text { I will read the official curriculum documents to identify the } \\
\text { specific learning goals and then use the teaching ideas and } \\
\text { resources that they suggest. }\end{array}$ & 4.5 & 21 \\
\hline
\end{tabular}

ranking process, and the limited responses in some cells, it was not meaningful to perform statistical tests on differences, but inspection of the distributions indicated that there were no important differences between the responses of teachers to these items, or to any of the following tables, based on these characteristics.

We also inspected the responses categorised by state. The two most populous states, New South Wales and Victoria have had quite different approaches to the presentation of and expectations about the use of formal curricula. The numbers of teachers were also too small to allow statistical comparison, but it was clear that, for secondary teachers the profile of the ranking was similar for these two states. It is possible that the planning routines of teachers in NSW and Victoria are similar despite differences in the presentation of curricula.

In the results overall, there is clearly a diversity of responses which suggest that teachers adopt different priorities and processes in their planning. Some base their planning on judgments and activities, others refer to official curriculum documents, others to texts (although fewer than we had anticipated for these secondary teachers) and a smaller number rely on school-developed documents. Indeed, even the most highly ranked option, that of collecting relevant classroom activities, was only selected in the top two factors by just over half of the teachers. While some of these secondary teachers reported using a commercial text, this was only around one third of respondents, suggesting that the common impression that secondary teachers rely heavily on commercial texts for planning may be overstated.

Another theme, arising across all the responses, is that teachers report making active judgments about what their students need and plan accordingly. Rather than simply 'implementing' formal curriculum documentation, these teachers appear to make ongoing decisions about the content of their teaching.

A third observation is that planning seems to be an individual rather than collaborative enterprise for these secondary teachers. This is discussed further later. 
Because we were not sure that the options we offered represented the planning processes of all teachers, the responders were also invited to respond to the following prompt:

If none of the statements in the question above are at all close to a description of how you would plan this topic, please write a description of how you would plan your next mathematics topic:

There were only 16 written responses, which we interpret to indicate that most teachers felt that their specific planning processes were represented in the list of options. On other similar items on the survey, there were many more teachers who gave written responses. Of the teachers who did respond, the responses were sophisticated and detailed, although some of the responses were merely restatements of one of the options offered. There were, though, responses that indicated that teachers' planning went well beyond the statements in the table. For example:

Identify the learning from Australian curriculum document. Look to see how new texts have interpreted the content. Reflect on what they have said, consider what I know already about the topic and the students' existing knowledge. Consider where the topic goes and what preparation is needed for future topics. Gather all relevant and interesting resources. Select for engagement.

I would obtain the topic to be taught from the schools' program. Using the official text book I will prepare a lesson plan, develop warm-up exercises, lesson presentation (may involve, overheads, PowerPoints, physical models), class work (taken from textbooks, or material I have available (or available from school), homework, end of topic test.

On one hand, the descriptions in Table 2 were considered adequate by most teachers to explain their planning processes. On the other hand, there were some teachers who gave written descriptions outlining complex and multi-step planning. This is discussed further below.

\section{Primary teacher responses}

The primary teachers also were invited to rank the same items after they had nominated the next topic they were to teach. Their responses are presented in Table 3. The meaning of the scores is the same as for the previous table.

The top two options for these primary teachers were also the most highly ranked by the secondary teachers, with the main difference from the secondary response being that the primary teachers gave a higher ranking to planning with other teachers. As for the secondary teachers, there is a diversity of ways that these primary teachers plan and it can be inferred that they make active decisions in their planning. The primary teachers gave a lower ranking to referring to a text as part of the planning process, but a much higher ranking to meeting with other teachers. As with the secondary teachers, the profile of response was similar across those various background variables presented in Table 2 .

The primary teachers, like the secondary teachers, were invited to describe their planning if none of the above descriptions matched the way they plan. There were 
Table 3 Ranking of statements on the planning process in order (primary) $(n=117)$

\begin{tabular}{|c|c|c|}
\hline & Mean ranking & $\begin{array}{l}\% \text { Ranking this } \\
\text { in the top two }\end{array}$ \\
\hline $\begin{array}{l}\text { Based on what I know about the students already, I will } \\
\text { collect the relevant classroom activities to which I have } \\
\text { access, choose the ones that fit the topic, and then decide } \\
\text { the order in which I will use them. }\end{array}$ & 2.6 & 52 \\
\hline $\begin{array}{l}\text { I will read the official curriculum documents to } \\
\text { identify the specific learning goals and then plan } \\
\text { my teaching based on that. }\end{array}$ & 2.8 & 48 \\
\hline $\begin{array}{l}\text { I will meet with other teachers, we will share our } \\
\text { experience and ideas, then plan the activities and } \\
\text { resources we will use. }\end{array}$ & 3.23 & 48 \\
\hline $\begin{array}{l}\text { I will look at the school-based curriculum documents } \\
\text { then identify specific learning goals, and select activities } \\
\text { from there that I will use with my students. }\end{array}$ & 3.7 & 20 \\
\hline $\begin{array}{l}\text { I will read the official curriculum documents to identify } \\
\text { the specific learning goals and then use the teaching } \\
\text { ideas and resources that they suggest. }\end{array}$ & 3.9 & 23 \\
\hline $\begin{array}{l}\text { I will look through a textbook or other teacher resource and } \\
\text { plan teaching which relates to the given content. }\end{array}$ & 3.7 & 0 \\
\hline
\end{tabular}

also just 13 replies indicating that the options offered in the table were meaningful descriptions of their planning. The responses were read and categorised. Some of the additional descriptions focused on the role of the team. An example of such a response is as follows

Discuss with team members the skills and understandings required to have students develop a deep understanding of the concept. Question what it is we want the students to learn. This may require doing some professional readingreading research or other reference material. Select a learning experience that provides the opportunity for students to showcase what their current understandings are and also that may provide insight into misconceptions the student may have. Make decisions where to next.

An example of a comment that emphasised the role of pedagogy is:

Although I rated the above $1-6$ in reality I pre-test the children on the concept then through discussion we share their results and knowledge then I pose questions relating to the concept (to engage their lateral thinking skills) we then go back and discuss then I show examples then I ask them to write examples and come to front of their class and reflect. The children then reflect on that child's knowledge etc. This is a cycle and over an hour lesson we can reflect on many concepts and take the understanding of each concept to a deeper level. I use texts, curriculum doc to guide me. I rarely give out a work sheet.

One of the responses indicated an emphasis on integration across topic boundaries. 
I will consider my students' current understanding of the topic (sampling and distribution) based upon the level of understanding they have demonstrated already. I will then devise an inquiry topic which will necessitate deep exploration of sampling (beyond their current understandings) in order for the students to resolve the inquiry question, regardless of what line of approach they take. I will ensure that the inquiry cannot possibly have a 'correct' answer which will necessitate the students gathering and presenting evidence to argue and justify their solutions in class. I will then look at the curriculum documents for my state, recognise that my students are working well above where they are 'supposed' to be, shrug it off and advise them of that because it amuses them that EQ thinks they are incapable of such deep understandings at their age.

Again these free format responses illustrate the complexity and sophistication of some teachers' planning routines. This is also discussed below.

\section{Use of assessment information}

In the focus groups, teachers gave prominence to their use of assessment information in their planning, so we sought to explore this further in the survey. The particular prompt also built on teachers having indicated their next topic and the associated important idea:

Rank the following statements in order from 1 to 6 in terms of "closeness" to how you will use assessment information in planning your next mathematics topic (use one for most like you, two for next most, etc.)

The options presented were selected from comments made by focus group teachers and were intended to represent the possible planning approaches we had identified.

\section{Secondary teacher responses}

Table 4 presents that ranking of the statements by secondary teachers on the use of assessment information. The interpretation of the scores in the table is the same as described before Table 2 .

The top two options are highly ranked by the teachers. The top two categories both refer to teachers using assessment information to determine the level of complexity at which they will plan their teaching, including their responses to differences in student readiness. Many teachers report planning around the middle level of the students, and others intend to group students and plan different activities for the students. This suggests that such teachers do use assessment data, although in each case in quite different ways. This has implications for future professional learning of secondary teachers, especially given that it can be inferred that the respondents are well informed about the planning options available to them. Note, though, that the assessments they use in this way are not externally determined ones.

The teachers were also invited to respond to the following: 
Table 4 Ranking of statements on use of assessment information in the planning process in order (secondary) $(n=115)$

\begin{tabular}{llc}
\hline & Mean ranking $\begin{array}{c}\text { \% Ranking this } \\
\text { in the top two }\end{array}$ \\
\hline $\begin{array}{l}\text { I will use assessment data to get a general sense of where my } \\
\text { children are at, and choose activities which are around the } \\
\text { middle level of their understanding }\end{array}$ & 2.3 & 63 \\
$\begin{array}{l}\text { I will use assessment data to group my students and plan different } \\
\text { activities for different groups, based on what I think they need. }\end{array}$ & 2.4 & 61 \\
$\begin{array}{l}\text { I will use assessment data to select a group with whom I'll work } \\
\text { closely during the topic (possibly a different group each day), } \\
\text { while the rest of the class work largely independently. }\end{array}$ & 3.7 & 25 \\
$\begin{array}{l}\text { I will not use assessment data but will rely on my own } \\
\text { judgments or on what other teachers tell me. }\end{array}$ & 4.0 & 25 \\
$\begin{array}{l}\text { I will analyse our students' responses to particular items on an } \\
\text { externally set assessment and use the results to plan my teaching. }\end{array}$ & 4.5 & 16 \\
$\begin{array}{l}\text { I will use the overall comparisons of our students with the State } \\
\text { mean and make judgments that inform my teaching. }\end{array}$ & 4.9 & \\
\hline
\end{tabular}

If none of these are at all close to how you will use assessment information, please give a brief summary of how you will use assessment data in your planning for the next topic:

There were 28 additional written comments indicating that a number of teachers did not consider the prompts offered to be adequate to explain their use of assessment information. Many of the written responses indicated that teachers wish to emphasise that they use assessment information to inform their teaching in thoughtful and nuanced ways.

For example:

I certainly use assessment data but not in the ways described above. Any issues indicated by the data are discussed with the class. Coming up with solutions is a collaborative activity. If it's an issue for most students then I'll address it in class-e.g. revise a topic that wasn't understood the first time. But for issues that arise for only a few students I'll address outside of class-e.g. extra tutorial assistance.

In contrast, some of the teachers reported that they use assessment mainly as an evaluative tool as evidenced by these responses:

I will identify deficiencies in student knowledge. I will plan to put more emphasis on correcting these particular deficiencies when possible. I would spend some time outside class time with selective students to help them overcome the deficiencies.

I will teach the students all the work that is required from the syllabus, extending their abilities to develop deep understanding of the topic. Then assess their learning to determine if further clarification is needed or more practise is required. 
The written responses indicate that these teachers plan their teaching using a number of different sources of information.

\section{Responses of primary teachers}

The same prompt was also used on the primary version of the survey. Table 5 summarises the responses of the primary teachers. The primary teachers were offered an additional option.

The two top statements are highly ranked by the teachers. One of the favoured prompts, using assessment data to group students, was the same as for secondary teachers. The other favoured prompt was different for these primary teachers. While the secondary teachers indicated they would use the assessment information to teach to the notional middle, the primary teachers indicated that they use assessment information to adapt content to students' needs. As with the secondary teachers, the teachers did not report using externally set assessment data.

There were eight written comments indicating the suggested prompts adequately described the use of assessment information by most of the respondents. Some written responses elaborated complex ways they use assessment information, such as:

Same process as above except I usually create my own assessment tasks. I believe less is more. Assess the same concept from one example of three different perspectives and I have a strong indication on the child's understanding of the concept. Child-centred discussions, relevant questioning and an emotionally

Table 5 Ranking of statements on use of assessment information in the planning process using assessment in order (primary) $(n=88)$

Mean ranking \% Ranking this in the top two

I will use assessment data to group my students and plan

different activities for different groups, based on what I think they need.

I will use assessment data to choose a given main a ctivity for each lesson, adapting the main activity for different levels of understanding

I will use assessment data to get a general sense of where my children are at, and choose activities which are around the middle level of their understanding

I will use assessment data to select a group with whom I'll work closely during the topic (possibly a different group ach day), while the rest of the class work largely independently.

I will analyse our students' responses to particular items on an externally set assessment and use the results to plan my teaching.

I will not use assessment data but will rely on my own judgments or what other teachers tell me.

I will use the overall comparisons of our students with the State mean and make judgments that inform my teaching.
7

$4.8 \quad 6$

5.8 
supportive climate will allow children to take risks thus develop a passion for maths and be engaged as there is always somewhere or someone to go to for further acquisition of knowledge. Develop a learning community not a didactic teacher lead pedagogy.

I use different strategies at different times of the year. Because I need to cover certain content before the end of the year, Term 4 seems to be driven by our scope $\&$ sequence. However this is heavily informed by recent NAPLAN results, as well as data from SENA results conducted earlier in the year. This is also coupled with observations, professional judgement and the needs of specific students as they have presented themselves.

It is clear that some teachers use assessment information in sophisticated ways. It does seem that primary teachers report using assessment information in ways that are more compatible with generic teaching advice than do the secondary teachers.

\section{Discussion and Conclusions}

The results reported above are from a survey of Australian teachers on aspects of their use of curriculum, the sources of authority they access, the way they identify the focus of their teaching, and their planning and assessment processes. We acknowledge that the teachers who took the time to complete the survey may not be representative of the teaching population overall. Yet, in terms of the schematic presented in Fig. 1, the results inform our understanding of teachers' curriculum knowledge, the opportunities and constraints they experience especially associated with curriculum authority, and their intentions to act, especially around their topic planning and assessment. There are some important implications for those who support mathematics teachers.

In terms of the first research question presented above, that connects with the opportunities and constraints element of the schematic in Fig. 1, the two most significant results could be characterised as "most expected" and "most unexpected." There was nothing surprising about the much greater contribution of commercial texts books to the planning processes of secondary mathematics teachers in comparison with their primary colleagues. Such a result, however, instils confidence in the results of the survey through its consistency with widespread experience (the researchers' and the community's as reported in focus group discussions). By contrast, the significant role accorded by both primary and secondary teachers to the teachers' own assessments was a surprise. This finding, confirmed and elaborated in focus group discussions and in subsequent teacher workshops, demonstrates the capacity of the survey to produce the unexpected and inspires further confidence in the instrument as doing more than just replicating the researchers' intuitions. At a time when the instructional use of technology persistently falls short of the reform aspirations of the education community, the use by primary and secondary teachers of online resources to support their planning validates the commitment by curricular authorities to the development and maintenance of such resources and represents a rare example of the utilisation by teachers of available technologies for educational purposes. 
In relation to the second research question, that connects to the teacher knowledge aspect of the schematic, it seems that teachers may need support in articulating the 'important ideas' on which they will focus and the sequencing and interrelationship of these ideas. While nearly all teachers readily identified the next topic they were to teach, only around half described the 'important ideas' in any detail or with a level of clarity likely to assist them in their planning. Much formal curriculum documentationincluding the AC:M-is schematically organised around important disciplinary ideas. These findings suggest that there is a disjuncture between teachers' conceptualisation and articulation of curriculum knowledge, and the ways in which it is represented in formal curriculum documentation. This apparent schism has import for both classroom practice and systems-level policy development and dissemination. Certainly, it suggests the need for further research on how teachers express and employ curriculum knowledge. There is also a need to work with teachers to develop ways of engaging with curriculum documents that assist them in articulating important ideas to their students.

In relation to the third research question that connects with both teacher beliefs and their intentions, it seems that, far from there being uniformity in the ways that teachers plan, there is a diversity of emphases and levels of sophistication of planning processes in the responses reported above. These findings re-emphasise the dynamic process of curriculum interpretation and enactment that occur in classrooms: formal curriculum documentation is just one of many resources that teachers draw upon in their planning processes. This suggests that any professional learning on planning should start from the processes that teachers use, and that teacher educators and others should assist teachers to find ways to make their own processes better.

A theme, which comes through the response to all sections of the survey, is that, in relation to curriculum planning, teachers are relatively confident of their own autonomy, authority, and expertise, although they did also, in other aspects of the survey, note that teachers will need support. The responding teachers do not follow recipes and instructions but make their own decisions based on many factors, including their own judgments, and those of colleagues in the case of primary teachers, on what will increase the chances of their students learning. Teachers in our survey used various levels of curriculum documentation to inform their curriculum planning. The documents they use, however, often state or imply a more circumscribed and limited role for the teacher in curriculum decision-making than the teachers responding to our survey assume (Gerrard \& Farrell, forthcoming). Teachers can interpret curriculum documents in different ways, and the way they interpret the documents influences the level of autonomy they assume in relation to curriculum planning (Harris-Hart, 2009). Our survey suggests that teachers are accustomed to reading and interpreting curriculum documents in ways that allow them significant scope for making decisions about curriculum and pedagogy in their classrooms and schools. This practice has naturally continued with the introduction of the AC:M. In other words, teachers read curriculum documents as if they have agency, assume that many curriculum decisions are theirs to make, and go ahead and make those decisions. Therefore, curriculum developers, administrators, policy makers, school leaders and teacher educators are likely to have more real influence on curriculum planning in classrooms if they can find ways to support teachers in their decision making rather than trying to curtail it. Specifically writing scripted units or lessons is unlikely to facilitate the type of teacher decision making that can inform quality teaching. 
Primary teachers reported more emphasis on collaborative planning in comparison with secondary teachers, who claimed to plan by themselves. Given that these teachers are able to find the time and willingness to collaborate, this suggests that collaboration is possible. We speculate that it would assist secondary teachers if routines in schools were established to facilitate collaborative planning. Case studies currently being undertaken on current practice in individual schools suggest that such routines are present in many schools but not in any uniform or institutionalised fashion.

Finally, in relation to the fourth question that connects with teachers' intentions from the schematic, the results of the survey suggest that all teachers use a variety of class, school and centralised assessment information to guide decisions on their planning, and many teachers use this information to make decisions on grouping students. While many primary teachers also use assessment information to plan key tasks and then adapt those tasks, many secondary teachers reported using assessments to estimate the middle level of the class and teach to that. The significance of this should not be underestimated. The results of this survey indicate that assessment information, and in particular classroom-based assessment, acts as a powerful mediator in teachers' enactment of formal curriculum documentation. In the context of the $\mathrm{AC}: \mathrm{M}$, this suggests that system- and sector-level personnel, and teacher-educators, need to consider the integrated relationship of curriculum enactment and student assessment in their work with teachers to bring the new AC into enacted practice.

While the data are from Australian teachers on the way they interpret curriculum, there are implications for understanding curriculum processes internationally. Whether a curriculum is strictly prescribed or whether teachers determine their curriculum based on the textbook they use, the results presented above suggest that teachers exercise judgment and autonomy in their planning, they access resources broadly, they plan in diverse ways, and they use assessment data to inform their teaching. The results also suggest that teachers may need support in identifying the important ideas underpinning the mathematics topics they are teaching. Especially with respect to this last point, there could be more discussion among the mathematics education community about ways of supporting teachers in doing that.

\section{References}

ACARA (2012). Development of the Australian curriculum. Accessed Jan 2012 from http://www.acara. edu.au/verve/_resources/The_Shape_of_the_Australian_Curriculum_V3.pdf

Ball, S. J. (1997). Policy sociology and $\bar{c}$ critical social research. British Educational Research Journal, 23 , 257-274.

Braun, A., Maguire, M., \& Ball, S. J. (2011). Policy enactments in the UK secondary school: examining policy, practice and school positioning. Journal of Educational Policy, 25(4), 547-560.

Choppin, J. M. (2009). Curriculum-content knowledge: teacher learning from successive enactments of a standards-based mathematics curriculum. Curriculum Inquiry, 39(2), 287-320.

Clark, C. M., \& Peterson, P. L. (1986). Teachers' thought processes. In M. C. Wittrock (Ed.), Handbook of research on teaching (pp. 255-296). New York: Macmillan.

Clements, D. H. (2006). Curriculum research: toward a framework for 'research-based curricula'. Journal of Research in Mathematics, 38, 35-70.

Drake, C., \& Sherin, M. G. (2006). Practicing change: curriculum adaptation in the context of mathematics education reform. Curriculum Inquiry, 36(2), 153-187.

Fernandez, C., \& Cannon, J. (2005). What Japanese and U.S. teachers think about when constructing mathematics lessons: A preliminary investigation. The Elementary School Journal, 105(5), 481-498. 
Freebody, P., \& Muspratt, S. (2008). Uses and effects of The Le@rning Federation's learning objects: An experimental and observational study. Ministerial Council on Education, Employment, Training and Youth Affairs (MCEETYA), (p. 108), [at http://www.thelearningfederation.edu.au/tlf2/showMe.asp? nodeID=891]

Hamilton, M. (2009). Putting words in their mouths: The alignment of identities with system goals through the use of Individual Learning Plans. British Educational Research Journal, 35, (2), 221-242.

Harris-Hart, C. (2009). Performing curriculum: exploring the role of teachers and teacher educators. Curriculum Inquiry, 39(1), 111-123.

Hattie, J., \& Timperley, H. (2007). The power of feedback. Review of Educational Research, 77(1), 81-112. Heinmans, S. (2011). Education policy, practice and power. Educational Policy (pre-print March 14), 1-25.

Hill, H., Ball, D., \& Schilling, S. (2008). Unpacking pedagogical content knowledge: conceptualising and measuring teachers' topic-specific knowledge of students. Journal for Research in Mathematics Education, 39, 372-400.

Holmqvist, M., \& Wennås Brante, E. (2011). What is discerned in teachers' expressions about planning? Education Inquiry, 2(3), 497-514.

Keitel, C., \& Kilpatrick, J. (1999). The rationality and irrationality of international comparative studies. In G. Kaiser, E. Luna, \& I. Huntley (Eds.), International comparisons in mathematics education (pp. 241-256). London: Falmer Press.

Kilpatrick, J., Swafford, J., \& Findell, B. (Eds.). (2001). Adding it up: Helping children learn mathematics. Washington, DC: National Academy Press.

Jin, X. (2012). Chinese middle school mathematics teachers' practices and perspectives viewed through a Western lens. Monash University: Unpublished $\mathrm{PhD}$.

Levinson, B. A., Sutton, U. M., \& Winstead, T. (2009). Educational policy as a practice of power: theoretical tools, ethnographic methods, democratic options. Educational Policy, 23(6), 767-795.

Remillard, J. T. (2005). Examining key concepts in research on teachers' use of mathematics curricula. Review of Educational Research, 75(2), 211-246.

Remillard, J., Herbel-Eisenmann, B. A., \& Lloyd, G. M. (Eds.). (2009). Mathematics teachers at work: Connecting curriculum materials and classroom instruction. New York: Routledge.

Sherin, M. G., \& Drake, C. (2009). Curriculum strategy framework: investigating patterns in teachers' use of reform-based elementary mathematics curriculum. Journal of Curriculum Studies, 41(4), 467-500.

Shulman, L. S. (1986). Those who understand: knowledge growth in teaching. Educational Researcher, 15 (2), 4-14.

Stein, M. K., Grover, B. W., \& Henningsen, M. (1996). Building student capacity for mathematical thinking and reasoning: an analysis of mathematical tasks used in reform classrooms. American Educational Research Journal, 33(2), 455-488.

Superfine, A. C. (2008). Planning for mathematics instruction: a model of experienced teachers' planning processes in the context of a reform mathematics curriculum. The Mathematics Educator, 18(2), 11-22.

Thorsten, M. (2000). Once upon a TIMSS: American and Japanese narrations of the Third international mathematics and science study. Education and Society, 18(3), 45-76.

Yates, L., \& Grumet, M. (2011). Curriculum in today's world: configuring knowledge, identities, work and politics. In L. Yates \& M. Grumet (Eds.), World Yearbook of Education 2011-Curriculum in today's world: Configuring knowledge, identities, work and politics (pp. 3-14). London \& New York: Routledge. 